\title{
Polymer Nanocomposites
}

\section{Sabine Gressler, Stefanie Prenner, Andrea Kurz, Susanne Resch, Anna Pavlicek*, Florian Part*}

\section{Summary}

Various additives are added to plastics to either improve processability, change product properties or protect them against thermal, UV or light influences. In the case of a polymer nanocomposite, the additives have at least one dimension of less than $100 \mathrm{~nm}$ and can be found in the form of platelets, fibres or particles. They primarily serve to improve tensile strength, thermoformability, flame retardancy, optical and electrical properties, and the barrier properties of the plastic into which they are incorporated. Nanoadditives include layered silicates such as montmorillonite, carbon-based additives (e.g. carbon black, carbon nanotubes, graphene), nanoscale metal oxides (e.g. $\mathrm{SiO}_{2}, \mathrm{TiO}_{2}, \mathrm{Al}_{2} \mathrm{O}_{3}$ ), metals (e.g. nano-silver, -gold, -copper), or organic additives such as nanocellulose or lignin nanoparticles. In addition to reductions in resources and weight, nanoadditives also have the potential to replace harmful substances such as environmentally problematic halogenated flame retardants. Across the world, polymer nanocomposites are already being used in packaging materials, the automotive industry and transportation, aerospace and energy technology, as well as in sporting goods. However, company surveys in the Austrian automotive and electronics industries have shown that nanoadditives currently only play a marginal role in these sectors. The main reasons are problems with dispersibility, large-scale production, high costs, and uncertainty around their impact on humans and the environment. There are still considerable gaps in knowledge. More research needs to be conducted with regard to release, exposure and environmental behaviour.
* Corresponding authors: florian.part@boku.ac.at and anna.pavlicek@oeaw.ac.at

\section{Additives, properties, applications, environmental aspects}

\section{Introduction}

Plastics consist mainly of organic polymers (matrix) which are compounded with additives Therefore, plastics belong to the group of composite materials and are also called polymer composites. Additives are added to plastics such as polyester (e.g. polyethylene terephthalate, PET), polyolefins (e.g. polypropylene, $\mathrm{PP}$ ) or polyamides (PA) to either improve processability, to change product properties, or to protect them against heat or UV light. Plastic additives include antioxidants, light stabilisers, polyvinyl chloride (PVC) stabilisers, acid scavengers, surface-active additives, nucleating agents and transparency enhancers, colourants, optical brighteners, expanding agents, flame retardants (FRs), fillers, and reinforcing agents. In addition, biocidal additives can also be added. ${ }^{1}$ In recent decades, the research field of plastic additives has developed rapidly through the use of nanomaterials. ${ }^{2}$ In a nanocomposite, the additives have at least one dimension in an order of magnitude of less than $100 \mathrm{~nm}$ and can be in the form of platelets, fibres or particles. Above all, they serve to improve tensile strength, heat resistance, flame retardancy, optical and electrical properties, and the barrier properties of the plastic.

As the interacting interfaces between nanoscale additive and matrix are much larger than for microscale additives, much smaller amounts $(<5 \%$ by weight) are required to achieve the desired properties, making a nanocomposite material lighter than a conventional polymer. ${ }^{3}$ In order to facilitate processing and uniform distribution (dispersion) in the polymer, the particle surface of nanoscale additives (nanoadditives) is usually modified. ${ }^{4} \mathrm{Na}$ noadditives can also be added to biobased plastics made of starch, cellulose or polylactic acid to improve the properties. Specific applications can be found especially in electronics, packaging materials ${ }^{5}$, in the automotive and aircraft industry, for medical engineering, and in sports equipment.

This dossier provides an overview of the various types of nanoadditives and their applications in practice as well as in research and development. In addition, environmental aspects along the product life cycle of nanocomposites are discussed.

\section{Nanoadditives}

\section{Layered silicates [nanoclay]}

Layered silicates, such as kaolin, talc or montmorillonite, are naturally occurring clay minerals and are amongst the most frequently investigated nanomaterials for the production of polymer nanocomposites. ${ }^{3}$ Montmorillonite in particular is the subject of numerous research projects and is already used commercially. Nanoscale montmorillonite is a sodium aluminium silicate and also called nanoclay because these layered silicates have at least one dimension in the nanometre scale. The thickness of the platelets is only one to a few nanometres, the length spanning from several hundred to thousands of nanometres. The mechanical properties of plastics, such as tensile and impact strength as well as heat distortion resistance, can be improved by adding layered silicates. In addition, such polymer nanocomposites exhibit high resistance to chemicals and good barrier properties to gases. ${ }^{5}$

As shown in Figure 1, nanoclays, which are added to, for example, polypropylene or polylactic acid packaging films, prevent the diffusion of oxygen or flavourings and thus prolong the shelf life of foods. Layered silicates occur naturally in large quantities and can also be produced synthetically at low cost. ${ }^{6}$ A homogeneous distribution of the platelets in the plastic matrix is crucial for improving the properties. For this, the platelets, which are naturally present in the form of packages, need to be surface-modified to facilitate the separation of the individual platelets (intercalation or exfoliation) and thus their dispersibility. The high aspect ratio of the platelets, i.e. the very small thickness in relation to width and length, results in a large interface between matrix and silicate so that only a few weight percent are sufficient to significantly improve the mechanical properties of the composite compared to the pure plastic. For example, the tensile strength of polystyrene/montmorillonite composites can be increased by $70-560 \%$ depending on particle distribution and surface treatment. The elastic modulus increases by a factor of 7 to 10 . The abrasion and scratch resistance of surfaces is also increased. ${ }^{6}$ 
Polymer-layered silicate nanocomposites are already used in packaging materials such as plastic bottles for carbonated beverages. Car parts such as timing belts, body parts and fuel tanks have been made of a polyamide montmorillonite composite material (nylon-6) since $1993 .{ }^{7}$ Especially in the automotive and aeronautics industries, weight reduction plays an important role in reducing fuel consumption. In the production of body parts, the use of polymer composites reinforced with nanoclay instead of steel promises possible advantages in order to save energy and reduce $\mathrm{CO}_{2}$ emissions. ${ }^{8}$

Montmorillonite can also reduce the flammability of polymer composites, which is why such composites are also suitable for the manufacture of products that have higher flame protection requirements (e.g. cable sheathing). Layered silicates thus have the potential to replace or at least reduce the use of environmentally problematic FRs such as halogenated compounds when used in combination with other FRs. ${ }^{9}$

For the flame-retardant effects to emerge, the formation of a thermally insulting crust layer that is only slightly permeable for volatile degradation compounds is pivotal. ${ }^{10}$

Bio-based plastics, for instance made of starch, are sensitive to moisture and often have poor mechanical properties. The addition of nanoclay can improve the properties considerably and even accelerate the disintegration or decomposition of biodegradable plastics, as first investigations have shown. ${ }^{11}$

Layered silicates are non-toxic, but under certain conditions they can release aluminium ions which are potentially harmful to human health. Therefore, legal requirements are in place for the use of polymer montmorillonite composites in food

Figure 1:

Intercalated (a) or exfoliated (b) nanoplatelets which improve the barrier properties of plastics.

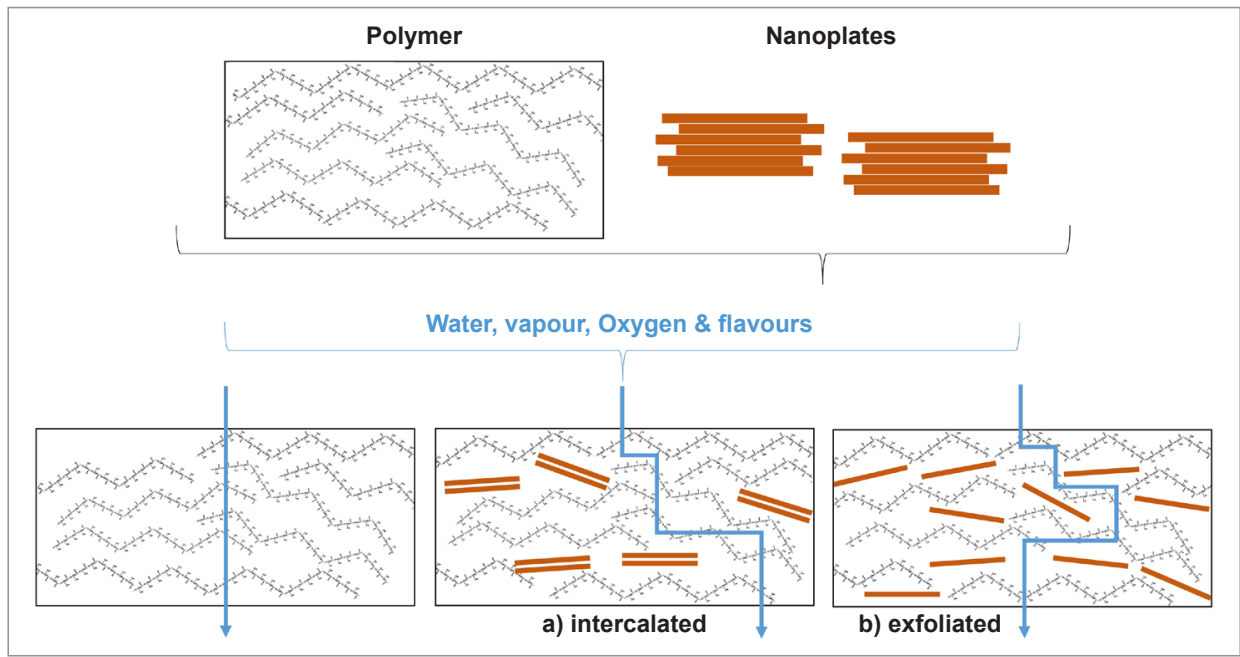

The German Federal Highway Research Institute estimates that the annual amount of particulate matter released through wear and tear from car tyres is approximately 111,000 t. For Austria, this would correspond to a quantity of about 12,000 t per year (simplified conversion by the number of inhabitants). The largest proportion of abraded particles consists of rubber and other polymers $(38 \%)$ as well as carbon black $(34 \%)$, the remainder of volatile substances, zinc and heavy metals. ${ }^{16}$ In a laboratory-scale release study of different rubber compounds, tyres were subjected to a mechanical fragmentation process that simulated abrasion whilst driving. Following this stress on the tyres, two different analysis scenarios were created in which rainy days and days without rain were simulated. The particles originally released as a result of these scenarios were further reduced in size by hydrolysis and UV processes. Results of this study showed that approx. $4.5 \%$ of the released particles were below $5 \mu \mathrm{m}$ and up to $0.045 \%$ in the nanometre range. ${ }^{17}$ The release of such microparticles and nanoparticles leads to increased pollution with particulate matter and/or ultrafine particles along roads, and subsequently to air pollution and respiratory or cardiovascular diseases. ${ }^{18}$ With regard to circular economy, in 2017 around $5 \%$ of collected used tyres in Austria were retreaded and $41 \%$ were recycled (approx. 54\% are thermally recovered). ${ }^{19}$ During the recycling process, the used tyres are mechanically shredded, which can also result in airborne emissions. ${ }^{20 ; 21}$ However, there are no further detailed studies on this subject. The resulting plastic regranulate is then used for road construction, in sports facility construction, the rubber industry, etc. ${ }^{22}$ Most likely, an unknown percentage of the originally used nanoadditives can be found in the regranulate, resulting in unintentional transfer into various recycling products.

The use of nanomaterials such as carbon black or nanoclay in tyres can therefore have both positive and negative effects on the environment (e.g. reduced fuel consumption due to reduced rolling resistance vs. particle release due to tyre abrasion). In 2014, the Organisation for Economic Cooperation and Development (OECD) carried out a study to investigate as comprehensively as possible any positive or negative effects along the life cycle - from manufacture to disposal. Several analytical tools were used in the study: a costbenefit analysis, a multi-criteria analysis, and a lifecycle analysis. Based on current information, the positive effects of silicon dioxide and nanoclay would predominate, especially during the production and use phase. However, the available data was subject to too much uncertainty in order to be able to make generally valid statements. For the provision of quantitative, reliable data, industry-specific guidelines and closer cooperation between the responsible authorities and industry are therefore required. ${ }^{23}$

At present, more and more research is being conducted into the use of carbon nanotubes (CNTs) as additives in tyre production. ${ }^{17} \mathrm{CNTs}$ consist of graphite-like carbon. They have a diameter of 
about 1 to $100 \mathrm{~nm}$ and can be as long as a few micrometres or even millimetres. CNTs can be divided into single-walled carbon nanotubes (SWCNTs) and multi-walled carbon nanotubes (MWCNTs). CNTs have unique mechanical and electrical properties and are suitable for numerous applications. ${ }^{24}$ Another class of carbonbased nanomaterials is graphene which consists of a monatomic layer of pure carbon with a thickness of only about $0.3 \mathrm{~nm} .{ }^{25}$ Graphene can be oxidised to graphene oxide which can also be used as an additive in plastics.

Because of their high tensile and impact strength, chemical resistance as well as their possible low specific weight, nanocomposites with CNTs and graphene are particularly interesting for applications requiring materials that are as light or as hard and resistant as possible. This applies particularly to areas that are closely linked to lightweight construction such as transportation, space travel, energy technology, or sports equipment such as bicycles. Such nanocomposites are also of interest for the manufacture of rotor blades for wind turbines. ${ }^{26}$ CNTs and graphene are also suitable for the production of electrically conductive thermoplastic polymer composites, for example for packaging electronic components, or in the automotive sector for fuel systems. Because of its excellent heat dissipation properties, graphene is also interesting for the manufacture of electrical and electronic products as excessive heat generation significantly reduces their service life. ${ }^{27}$ Moreover, the FR effect of these nanoadditives is also of interest. The production of graphene and CNTs is still relatively expensive and the quality of the available additives does not yet meet the requirements of the industry. This and technical problems with a homogeneous distribution in the matrix still represent obstacles for a broad application of polymer nanocomposites with graphene and CNTs, resulting in specific applications currently being limited to special productions or niche products. ${ }^{26}$ The unique properties of graphene and its manifold applications - from heat-resistant, high-strength polymer composites to highly efficient solar cells and scratch-resistant automotive coatings - are currently being researched as part of the EU project Graphene Flagship. ${ }^{28}$

With regard to aspects of worker protection, CNTs pose a health risk because of their similarity to asbestos fibres. ${ }^{29}$ If the additives are firmly embedded in a matrix, the current state of knowledge indicates that the risk to humans and the environment is low, but that it cannot be completely ruled out. ${ }^{30}$ However, there are still considerable gaps in knowledge regarding release, exposure and environmental behaviour. ${ }^{31}$ In addition to production, possible release pathways that could occur during the life cycle of nanocom- posites can be found in processing or waste treatment into which nanoadditives can be released by milling, drilling, shredding or burning. First investigations show that at temperatures above $850^{\circ} \mathrm{C}$, MWCNTs burn completely, but graphene platelets remain in combustion residues. If CNTs or graphene are used as additives in biodegradable plastics, they may also be released during the degradation process (e.g. in landfill or a mechanical-biological waste treatment plant). ${ }^{32}$ With regard to possible environmental relief potentials and sustainability effects, e.g. through resource savings because of a weight reduction in materials, comprehensive lifecycle analyses are still lacking and currently still subject to great uncertainties because of a lack of data. ${ }^{33}$; 34 The behaviour of nanoadditives during waste treatment or landfilling is currently also not known; the release from landfills, especially in countries where no waste pre-treatment prior to landfilling is required, cannot be excluded, and mobility in landfill leachates depends on the prevailing environmental conditions (mainly organic matter and electrolyte content) and on the original surface modification (particle coating) of the nanomaterial. ${ }^{35}$

\section{Nanometals and

nanometal oxides

Silicon dioxide $\left(\mathrm{SiO}_{2}\right)$, aluminium oxide $\left(\mathrm{Al}_{2} \mathrm{O}_{3}\right)$ and titanium dioxide $\left(\mathrm{TiO}_{2}\right)$ are the most frequently used nano-oxides in polymer composites, mainly to increase resistance to mechanical influences and to reduce wear. Heat resistance can also be improved by using nano-oxides. ${ }^{3} \mathrm{TiO}_{2}$ nanoparticles can also serve as UV protection for plastics. ${ }^{36}$ FRs must be added to plastics to provide fire protection. In recent decades, the use of nanoscale $\mathrm{FRs}$ such as ultrafine aluminium hydroxide $\left(\mathrm{Al}(\mathrm{OH})_{3}\right)$, magnesium hydroxide $\left(\mathrm{Mg}\left(\mathrm{OH}_{2}\right)\right)$ or antimony oxide $\left(\mathrm{Sb}_{2} \mathrm{O}_{3}\right)$ has been researched. ${ }^{2}$ In addition, ultrafine $\mathrm{Sb}_{2} \mathrm{O}_{3}$, zinc borate, doublelayer hydroxides (e.g. hydrotalcite or polyhedral oligomeric silsesquioxane (POSS)), but also nanoclay and CNTs, are used as so-called synergists to improve the flame retardancy of other FRs. ${ }^{2}$ These halogen-free nanoadditives have great potential to replace halogenated FRs which are partly carcinogenic and hormone-active, and have therefore been banned in the EU (e.g. octabromodiphenyl ether). ${ }^{37}$

Nanosilver has an antimicrobial effect and can be used in plastics, for example to manufacture food packaging such as films or containers to protect food from spoilage. However, nano-silver has not yet received approval for food contact materials in the EU as there are concerns about possible risks to human health and in particular to the environment if dissolved ions from nanosilver particles enter the aquatic environment. ${ }^{38}$
In addition, nano-silver, like nano-gold and nanocopper, graphene platelets, graphene oxide or CNTs, is used in flexible electronic devices because of its electrically conductive properties.

Using 2D printing, inks containing nanomaterials are applied to various substrates such as polyethylene terephthalate (PET), polyimide (PI) or polyethylene naphthalate (PEN), but also to textiles and solar cells. ${ }^{39}$ The market for printed, flexible and organic electronics has been estimated at approximately USD 31 billion in 2018, and is expected to more than double over the next 10 years. ${ }^{40}$ In addition, 3D printing (also referred to as additive manufacturing) can be used to produce nanocomposites layer by layer. Research into 3D printing is being carried out primarily in the biomedical field where artificial tissue or artificial organs could be printed on the basis of natural or synthetic polymers and with the use of photoinitiators (PIs). ${ }^{41}$ In this context, nanoparticulate $\mathrm{Pls}$ are also being researched. For example, photocatalytic semiconductor-metal nanorods (CdSe/CdS-Au) can be used as Pls for 3D printing. ${ }^{42}$ During 3D printing, the PIs have the function of triggering the photopolymerisation of photosensitive monomers and oligomers. ${ }^{43}$ This technique produces socalled photopolymers, such as methacrylate-based resins, in order to tailor technical or medical components (e.g. special tools or nozzles). Together with ceramic nanofibers (zirconium-, silicon- and/or yttrium- based), photopolymers are also used for the production of dental fillings. ${ }^{44}$

\section{Organic nanoadditives}

Glass or carbon fibres are often added to plastics to increase their strength. However, the production of these fibres requires large amounts of energy. As a result, the focus is increasingly shifting towards alternatives made of natural fibres whose starting materials and production are considered to be largely harmless from an ecological point of view. ${ }^{45}$ Such organic additives are of particular interest for the production of biopolymer composites as they not only improve their properties but are also biodegradable. However, natural fibre-reinforced plastics do not yet come close to the quality of glass or carbon fibre composites as some technical problems still have to be overcome, e.g. the low adhesion of (hydrophilic) natural fibres to (hydrophobic) polymers. In addition, even distribution in the polymer matrix is extremely difficult and the quality of the natural fibres is subject to greater fluctuations than is the case with synthetically produced fibres as the weather and environmental influences have a direct effect on the properties of the fibres. 
Nanocellulose is gaining more and more interest from both research and industry because of its physicochemical properties such as high tensile strength, biocompatibility and high aspect ratio. ${ }^{46}$ Potential applications range from medicine to construction. Nanocellulose fibrils have strength and rigidity superior to that of glass fibres. They can be extracted in a top-down process from various renewable sources such as wood pulp, crops, or organic waste. Fibrillar diameters of up to $2 \mathrm{~nm}$ are possible, with a length of a few micrometres. Bacteria can also produce cellulose macromolecules from sugar and use them as a protective film. This film consists of highly purified nanocellulose with a proportion of crystalline structures of up to $90 \%$ and fibrillar diameters of 10 to $100 \mathrm{~nm}$ and a length of a few micrometers. 45 Nanocellulose has the potential to replace petroleumbased materials for the manufacture of films, coatings or packaging. According to currently available information, the material poses no risk to human health or the environment. ${ }^{47}$

Lignocellulose is a component of the cell walls of wooden plant parts and serves as a structural framework. The material consists of $40-80 \%$ cellulose, $5-25 \%$ lignin and $10-40 \%$ hemicellulose. Large quantities of wood and straw waste are available worldwide and are currently mainly used for energy generation. ${ }^{48}$ Lignin can also be extracted from such waste in biorefinery plants to produce lignin nanoparticles. These are the subject of research for a wide variety of applications. Lignin shows some outstanding properties such as high resistance to decay, UV absorption, high rigidity, and the ability to slow down or prevent oxidation processes. When, for example, incorporated into bioplastics, nanolignin can increase the strength of the plastic. Initial research results also show that this material would be suitable for UV protection or as a plastic additive because of its biocidal properties. ${ }^{48}$

\section{Current applications in practice}

As part of the "NanoAdd" 49 project, online market research was conducted to explore which consumer products containing nanocomposites are available on the Austrian market. Since manufacturers are not obliged to declare the composition of the plastics they use, it was only possible to identify products where manufacturers or retailers voluntarily provided information about the nanoadditives they had used.

The investigation revealed that, in the consumer goods sector, nanocomposite materials are being promoted only in a few sporting goods. The incorporated nanoadditives are graphene and
CNTs, i.e. carbon-based additives that are used in this context to make lighter and more durable products such as bicycle tyres, frames and helmets, sports shoes, and badminton rackets.

\section{Enterprise surveys}

In addition to online market research, qualitative data was collected from ten Austrian companies (compounders, processors, research and development) in 2019. This survey investigated if and to what extent nanoscale additives are used in plastic parts, with a particular focus on the automotive and electrical/electronics industries. In addition, assessments were carried out on trends and expected future developments for the use of nanoadditives in these areas.

In contrast to the scientific literature, where the application of nanoadditives to various products in the automotive and electrical/electronics industries is demonstrated on a laboratory scale, very few, if any, nanomaterials are currently being used in practice in these areas. In these sectors, carbon black is mainly used as a black pigment. The majority of the interviewed processors do not perceive carbon black as a nanofiller because a more coarse and microscale carbon black is typically used. Ultrafine or nanoscale carbon black is currently only used for special foils. Furthermore, $\mathrm{TiO}_{2}$ particles are used as white pigments. However, it is unclear whether these additives used are nanoscale in size as the particles are already contained in the purchased masterbatch. ${ }^{50}$ In addition, some halogen-containing flame retardants are already being replaced by nanoclay (in combination with other synergists). In general, according to the companies surveyed, the majority of all nanoadditives are currently used in surface coatings and paints (e.g. nano- $\mathrm{TiO}_{2}$ as a photocatalytic coating).

In the field of applied research and development, nanoscale additives are increasingly being tested in the automotive sector as well as in electrical engineering and electronics. Examples include CNTs for modifying electrical conductivities, nanoscale glass additives to replace asbestos-like ingredients in self-lubricating bearings or graphene/-derivatives in nanoelectronics. At present, customers almost exclusively demand improved product functionality from research. According to the companies surveyed, sustainability plays a secondary role here as it has no unique selling point for durable products.

Reasons why nanomaterials are only used to a limited extent in the sectors studied are very similar for all interviewees: challenges regarding the dispersibility and production of nanocomposites on a larger scale (outside the laboratory), a steep price level, and an uncertain impact on humans and the environment. If these barriers can be overcome, some of the interviewees consider the use of nanoadditives as conceivable for the future. Some companies expect nanoadditives to add value in the future through improved properties such as temperature stability, scratch resistance, process simplification (single-stage process) or reduced weight, especially in the automotive and aeronautics industry. Resulting material savings and process simplifications would also have positive side effects for the environment. In general, however, the interviewees do not foresee an increase in the use of nanoadditives in the near future.

With regard to recycling and the associated accumulation effects, it is expected that fewer additives (both nanoadditives and conventional additives) will be used in plastics in the future. In addition, several of the questioned companies requested a general standardisation and reduction of the number of different plastic components. Specific regulations in the field of flame retardants, which play an important role for example in e-mobility, are seen as the starting point for this. Subsequently, general guidelines for the recycling of plastics should be created.

\section{Conclusion}

For the production of polymer nanocomposites, research has long been concerned with the use of a wide variety of nanoadditives. Nanoadditives have special properties which improve the mechanical, electrically conductive, biocidal, FR or barrier properties. Their use can result in both positive environmental effects (e.g. through savings in weight and the resulting resource savings) and negative effects (e.g. environmental risks due to release). However, a number of technical obstacles still need to be overcome for large-scale use. Moreover, market prices of many nanoadditives are still too high. It is also important to create a solid scientific basis so that health and environmental risks can be assessed sufficiently in advance in the course of a wellfounded risk assessment, thus ensuring the safe use of these materials. 


\section{References}

1 Maier R.D. \& Schiller M. (2016): Handbuch Kunststoff Additive. 4., vollständig neu bearbeitete Auflage. Carl Hanser Verlag, München.

2 Xanthos M. (2010): Functional Fillers for Plastics By Marino Xanthos (Ed.). WILEY-VCH Verlag.

3 Rallini M. \& Kenny J.M. (2017): Nanofillers in Polymers. In: Modifications of Polymer Properties. Elsevier. 4786.

4 Greßler S. \& Gazsó A. (2016): Oberflächenmodifizierte Nanopartikel - Teil I: Arten der Modifikation, Herstellung, Verwendung. NanoTrust-Dossier no. 046, Mai 2016

5 Gressler S., Part F., Gazsó A. \& Huber-Humer M. (2018): Nanotechnological Applications for Food Contact Materials. NanoTrust-Dossier no. 049en, July 2018

6 Langner R., Kohlhoff J., Grüne M. \& Reschke St. (2015): Schichtsilikat-Polymer-Nanokomposite. Werkstoffe in der Fertigung. HW-Verlag. https://werkstoffzeitschrift.de/schichtsilikatpolymer-nanokomposite/. Accessed 20.08.19.

7 How Toyota brought nanocomposite materials to the world. December 2014. https://blog.toyota. co.uk/toyota-brought-nanocomposite-materialsworld. Accessed 21.08.19.

8 Lloyd M.S. \& Lave L.B. (2003): Life Cycle Economic and Environmental Implications of Using Nanocomposites in Automobiles. Environ. Sci. Technol. 37, 3458-3466.

9 Pielichowski K. \& Michalowski S. (2014): Nanostructured flame retardants: performance, toxicity, and environmental impact. Health and Environmental Safety of Nanomaterials. Polyme Nanocomposites and other Materials containing Nanoparticles. 251-277. Woodhead Publishing.

10 Hessen-Nanotech (2009): Nanotechnologie in Kunststoff. Innovationsmotor für Kunststoffe, ihre Verarbeitung und Anwendung. Band 15 der Schriftenreihe der Aktionslinie Hessen-Nanotech des Hessischen Ministeriums für Wirtschaft, Verkehr und Landesentwicklung.

https://www.technologieland-hessen.de/mm/ NanoKunststoff_Nanotechnologie_Kunststoff_ Innovationsmotor_Verarbeitung_Anwendung.pdf.

11 Bergeret A. (2011): Environmental-Friendly Biodegradable Polymers and Composites. Integrated Waste Management, Vol. I. Kap. 18, 341-364. Sunil Kumar (Ed.). In Tech.

12 Zhang C., Cui F., Zeng G.M., Jiang M., Yang Z.Z., Yu Z.G., Zhu M.Y. \& Shen L.Q. (2015): Quaternary ammonium compounds (QACs): a review on occurrence, fate and toxicity in the environment. Sci Total Environ, 518-519, 352-362.

$13 \mathrm{DaNa}$ - Informationen zu Nanomaterialien und Nano-Sicherheitsforschung. Industrieruß (Carbon Black) -Materialinfo. https://www.nanopartikel. info/nanoinfo/materialien/industrieruss/ materialinfo-industrieruss. Accessed 22.08.19.

14 Paul D.R. \& Robeson L.M. (2008): Polymer nanotechnology: Nanocomposites. Polymer 49 (15), 3187-3204. 10.1016/j.polymer.2008.04.017.
15 Environment Canada, Health Canada (2013): Carbon Black: Screening Assessment for the Challenge. Environment Canada; Health Canada. https://www.ec.gc.ca/ese-ees/2CF34283-CD2B4362-A5D6-AD439495D0D1/FSAR_B12\%20-\% 201333-86-4\%20\%28Carbon\%20Black\%29 EN.pdf. Accessed 05.01.19.

16 Kocher B., Brose S., Feix J., Görg C., Peters A. \& Schenker K. (2010): Stoffeinträge in den Straßenseitenraum - Reifenabrieb. BASt-Bericht V 188. Bundesanstalt für Straßenwesen.

https://www.bast.de/BASt 2017/DE/Publikationen/ Berichte/unterreihe-v/2010-2009/v188.htm

17 Wohlleben W., Meyer J., Muller J., Müller P., Vilsmeier K., Stahlmecke B. \& Kuhlbusch T.A.J. (2016): Release from nanomaterials during their use phase: combined mechanical and chemical stresses applied to simple and multi-filler nanocomposites mimicking wear of nano-reinforced tires. Environmental Science: Nano 3, 1036-1051 10.1039/C6EN00094K

18 Foitzik M.-J., Unrau H.-J., Gauterin F., Dörnhöfer J. \& Koch T. (2018): Investigation of ultra fine particulate matter emission of rubber tires. Wear 394-395, 87-95. 10.1016/j.wear.2017.09.023.

19 Bundesministerium für Nachhaltigkeit und Tourismus (2019): Die Bestandsaufnahme der Abfallwirtschaft in Österreich: Statusbericht 2019. Accessed 02.08.19.

20 Bundesministerium für Nachhaltigkeit und Tourismus (2017): Bundes-Abfallwirtschaftsplan 2017, Teil 2. https://www.bmnt.gv.at/umwelt/abfallressourcen/bundes-abfallwirtschaftsplan/ BAWP2017-Final.html. Accessed 11.05.19.

21 Duncan T.V. (2015): Release of engineered nanomaterials from polymer nanocomposites: the effect of matrix degradation. ACS applied materials \& interfaces 7 (1), 20-39.

22 Mülsener Rohstoff- und Handelsgesellschaft $\mathrm{mbH}$, s.a. Anwendungen von Gummimehlen und Gummigranulaten in Industrie, Chemie, Bau, Freizeit, Sport. https://www.mrh-muelsen.de/mrhgummimehle-gummigranulate-altreifenrecycling. html. Accessed 02.08.19.

23 OECD (2014), Nanotechnology and Tyres: Greening Industry and Transport, OECD Publishing, Paris, https://doi.org/10.1787/9789264209152-en.

24 Gressler S., Fries R. \& Simkó M. (2012): Carbon Nanotubes - Part I: Introduction, Production, Areas of Application. NanoTrust Dossier no. 022en, February 2012.

$25 \mathrm{DaNa}$ - Informationen zu Nanomaterialien und Nano-Sicherheitsforschung. Graphen - Materialinfo. https://www.nanopartikel.info/nanoinfo/ materialien/graphen/materialinfo-graphen. Accessed 22.08.19.

26 Brandt H. (2017): Kohlenstoffbasierte Nanokomposite für Strukturanwendungen. Europäische Sicherheit und Technik. Juli 2017. Fraunhofer-Ins titut für Naturwissenschaftlich-Technische Trendanalysen berichtet über neue Technologien. 76 . https://www.int.fraunhofer.de/content/dam/int/de/ documents/EST/EST-0717-KohlenstoffbasierteNanokomposite-fuer-Strukturanwendungen.pdf. Accessed 22.08.19.
27 Chen Y., Gao J., Yan Q., Hou X., Shu Sh., Wu M. Jian N., Li X., Xu J.-B., Lin Ch.-T. \& Yu J. (2018): Advances in graphene-based polymer composites with high thermal conductivity. Veruscript Functional Nanomaterials, 2, \#OOSB06.

28 For more applications of graphene see: https://graphene-flagship.eu/material/ GrapheneApplicationAreas/Pages/default.aspx.

29 Fries R., Gressler, S. \& Simkó M. (2012): Carbon Nanotubes - Part II: Risks and Regulations. NanoTrust Dossier no. 024en, February 2012.

30 Nowack B., David R.M., Fissan H., Morris H., Shatkin J.A., Stintz M., Zepp R. \& Brouwer D. (2013): Potential release scenarios for carbon nanotubes used in composites. Environmental International 59, 1-11.

31 Gressler S. \& Nentwich M. (2012): Nano and Environment - Part II: Hazard potentials and risks. NanoTrust Dossier no. 027en, March 2012.

32 Kotsilkov S., Ivanov E. \& Vitanov N.K. (2018): Release of Graphene and Carbon Nanotubes from Biodegradable Poly(Lactic Acid) Films during Degradation and Combustion: Risk Associated with the End-of-Life of Nanocomposites Food Packaging Materials. Materials 11, 2346.

33 Gressler S. \& Nentwich M. (2012): Nano and the environment - Part I: Potential environmental benefits and sustainability effects. NanoTrust Dossier no. 026en, March 2012

34 Salieri B., Turner D.A., Nowack B. \& Hischier R (2018): Life cycle assessment of manufactured nanomaterials: Where are we? Nanolmpact, Volume 10, April 2018, Pages 108-120.

35 Part F., Berge N., Baran P., Stringfellow A., Sun W., Bartelt-Hunt S., Mitrano D., Li L., Hennebert P., Quicker P., Bolyard S.C. \& Huber-Humer M. (2018): A review of the fate of engineered nanomaterials in municipal solid waste streams. Waste Management 75, 427-449, https://doi.org/10.1016/j.wasman.2018.02.012.

36 Fries R. \& Simkó M. (2012): (Nano-)Titanium dioxide (Part I): Basics, Production, Applications. NanoTrust Dossier no. 033en, November 2012

37 Directive 2003/11/EC of the European Parliament and of the Council of 6 February 2003 amending for the 24th time Council Directive 76/769/EEC relating to restrictions on the marketing and use of certain dangerous substances and preparations (pentabromodiphenyl ether, octabromodiphenyl ether).

38 Fries R., Gressler S., Simkó M., Gazsó A., Fiedeler U. \& Nentwich M. (2010): Nanosilver. NanoTrust Dossier no. 010en, November 2010.

39 Kamyshny A. \& Magdassi S. (2019): Conductive nanomaterials for 2D and 3D printed flexible electronics. Chem. Soc. Rev., 2019, 48, 171. DOI: $10.1039 / \mathrm{c} 8 \mathrm{cs} 00738 \mathrm{a}$.

40 IDTechEx Ltd (2019): Flexible, Printed and Organic Electronics 2019-2029: Forecasts, Players \& Opportunities. https://www.idtechex.com/en/ research-report/flexible-printed-and-organicelectronics-2019-2029-forecasts-players-andopportunities/639. 
41 Murphy S.V. \& Atala A. (2014): 3D bioprinting of tissues and organs. Nature Biotechnology 32,773 10.1038/nbt.2958.

42 Waiskopf N., Ben-Shahar Y., Banin U. (2018): Photocatalytic Hybrid Semiconductor-Metal Nanoparticles; from Synergistic Properties to Emerging Applications. Advanced materials (Deerfield Beach, Fla.) 30, e1706697, 10.1002/adma.201706697

43 Peer G., Dorfinger P., Koch T., Stampfl J., Gorsche C. \& Liska, R. (2018): Photopolymerization of Cyclopolymerizable Monomers and Their Application in Hot Lithography. Macromolecules 51, 9344-9353, 10.1021/acs.macromol.8b01991.

44 Li X., Liu W., Sun L., Aifantis K.E., Yu B., Fan Y., Feng Q., Cui F. \& Watari, F. (2014): Resin Composites Reinforced by Nanoscaled Fibers or Tubes for Dental Regeneration. BioMed Research International 2014, 13, 10.1155/2014/542958.

45 Mautner A. (2016): Green Materials - Nanocellulose. Polymere. Plus Lucis 1/2016. 45-48. https:// www.univie.ac.at/pluslucis/PlusLucis/161/S45.pdf.

${ }^{46}$ Aspect ratio is defined as the ratio of fiber length to diameter.

47 Stoudmann N., Nowack B. \& Som C. (2019): Prospective environment risk assessment of nanocellulose for Europe. Environ. Sci.: Nano, 2019, 6, 2520-2531. https://pubs.rsc.org/en/ content/articlepdf/2019/en/c9en00472f.
48 Beisl St., Friedl A. \& Miltner A. (2017): Lignin from Micro- to Nanosize: Applications. Int. J. Mol. Sci. 18 https://www.vt.tuwien.ac.at/fileadmin/t/vt/TVT/Biorefinery/IntJMolSci_2017_18_2367_reduziert.pdf.

49 NanoAdd - The significance of functional fillers and nanoscale additives for plastics in the circular economy. Project no. 867865. Lead: University of Natural Resources and Life Sciences, Vienna (BOKU), Department of Water, Atmosphere and Environment (WAU), Institute of Waste Management (ABF). Funded by the Austrian Research Promotion Agency (Vienna), Programme NANO EHS. https://projekte.ffg.at/projekt/3060046.

50 Masterbatch is a solid or liquid additive for plastic used for coloring plastics (color masterbatch) or imparting other properties to plastics (additive masterbatch). Masterbatch is a concentrated mixture of pigments and/or additives encapsulated during a heat process into a carrier resin which is then cooled and cut into a granular shape. https://en.wikipedia.org/wiki/Masterbatch. Accessed 01.12.19.

\section{MASTHEAD}

Owner: Austrian Academy of Sciences; legal person under public law (BGBI 569/1921 idF BGBI I 31/2018);

Dr. Ignaz Seipel-Platz 2, A-1010 Vienna

Editor: Institute of Technology Assessment (ITA); Apostelgasse 23 A-1030 Vienna; www.oeaw.ac.at/ita

Mode of publication: The NanoTrust Dossiers are published irregularly and contain the research results of the Institute of Technology Assessment in the framework of its research project NanoTrust. The Dossiers are made

available to the public exclusively via the Internet portal "epub.oeaw": epub.oeaw.ac.at/ita/nanotrust-dossiers/

NanoTrust-Dossier Nr. 052en, February 2020: epub.oeaw.ac.at/ita/nanotrust-dossiers/dossier052en.pdf

(n)

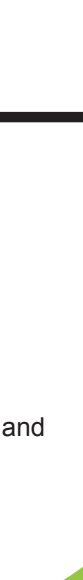

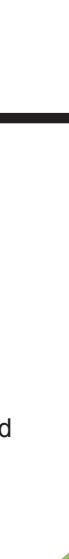

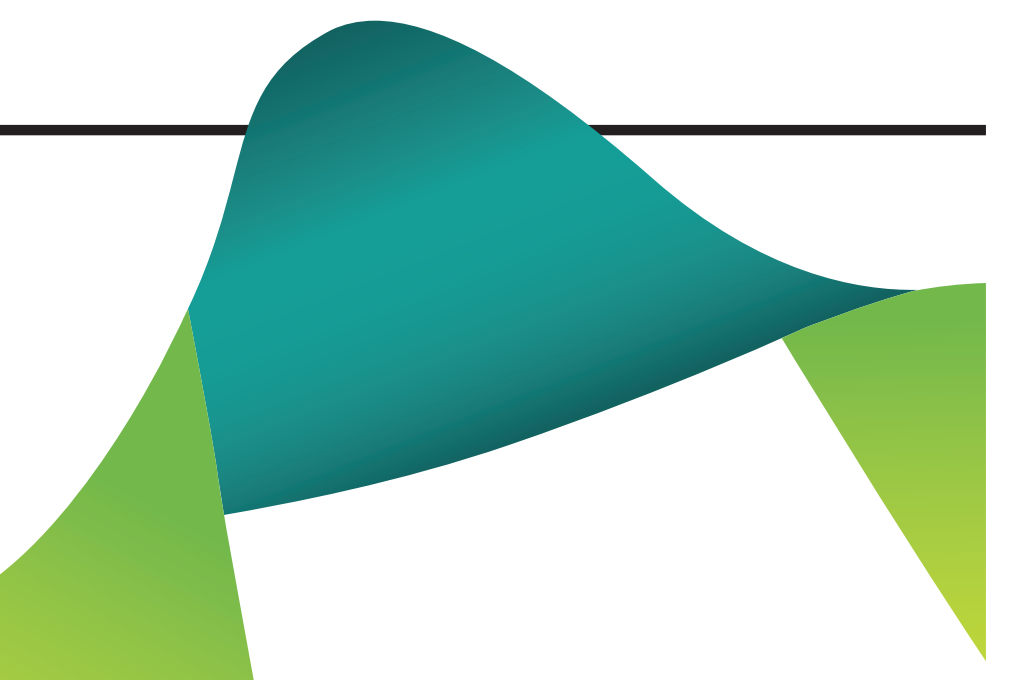

